\title{
Experiencia sobre el empleo de juegos en la educación superior
}

\section{An experience on the use of games in higher education}

\author{
MORÁN-SALAS, María Cristina†*, MOYA-JIMÉNEZ, Carlos Roberto y LEY-FUENTES, Martha \\ Georgina
}

Universidad de Guadalajara, CUCBA, SUV

ID $1^{\text {er }}$ Autor: María Cristina, Morán-Salas / ORC ID: 0000-0002-8458-2241, Researcher ID Thomson: T-4543-2018, CVU CONACYT ID: 948550

ID $1{ }^{\text {er }}$ Coautor: Carlos Roberto, Moya-Jiménez / ORC ID: 0000-0002-7582-5168, Researcher ID Thomson: X-5004-2019

ID $2^{\mathrm{do}}$ Coautor: Martha Georgina, Ley-Fuentes / ORC ID: 0000-0001-9456-869X, CUV CONACYT ID: 287542

DOI: $10.35429 / J E S C .2019 .9 .3 .1 .6$

Recibido: 13 de Julio, 2019; Aceptado 30 de Septiembre, 2019

\begin{abstract}
Resumen
Los juegos de mesa adaptados resultaron excelentes instrumentos didácticos en la educación superior. Con el objetivo de facilitar el aprendizaje y motivar la participación se adaptaron diversos juegos de mesa con temáticas de bacteriología se seleccionaron a 33 alumnos de tercer semestre de la licenciatura medicina veterinaria y zootecnia, de la Universidad de Guadalajara, se formaron equipos de trabajo para que seleccionaran un juego y lo adaptaran con la temática asignada, los juegos se reasignaron a otros equipos de tal forma que todo el grupo jugó todos los juegos. Para evaluar el aprendizaje se realizó un pretest y postest; además se midió el grado de satisfacción de la actividad mediante una encuesta empleando escala tipo Likert. Los estudiantes mejoraron su aprendizaje significativamente ( $\mathrm{p}<0.195$ E-08). El 91\% considera la estrategia útil y atractiva y el $83 \%$ se sintió motivado. De los juegos de mesa el más atractivo fue el Headbands. Los juegos son herramientas que facilitan el aprendizaje y motivan la participación y hacen divertidas las actividades escolares.
\end{abstract}

Juegos de mesa, Motivación, Aprendizaje

\begin{abstract}
The adaptation of board games as didactical instruments in superior education facilitates learning. With the objective of easing the learning process and incentivize participation various board games were adapted and combined with bacteriology topics. 33 students of third semester of the bachelor's degree in Veterinary Medicine and Zootechnics at the University of Guadalajara were selected to form work groups with the objective of selecting a board game and adapt it to the assigned thematic. Also, these games were reassigned to other work groups afterwards, with the finality that the whole class played with all the board games. To evaluate the learning rate in this dynamic project a pre-test and a post-test were realized; the degree of satisfaction was also measured through a survey using a Likert type scale. The students improved their learning exponentially $(p<0.1 .95 \mathrm{E}-08)$. $91 \%$ of the sample considers the strategy useful and attractive and $83 \%$ of the previous sample felt motivated towards the topics. Of all of the board games used the most engaging one was "Headbands". Board games are tools which facilitate the learning process and motivate participation while making scholar activities fun and entertaining.
\end{abstract}

Boar games, Motivation, Learning

Citación: MORÁN-SALAS, María Cristina, MOYA-JIMÉNEZ, Carlos Roberto y LEY-FUENTES, Martha Georgina. Experiencia sobre el empleo de juegos en la educación superior. Revista de Ciencias de la Educación. 2019. 3-9: 1-6

\footnotetext{
* Correspondencia del Autor (correo electrónico: maria.msalas@academicos.udg.mx)

$\dagger$ Investigador contribuyendo como primer autor.
} 


\section{Introducción}

A consecuencia del avance de la era digital y de las tecnologías de la información, se han producido cambios en las necesidades de los estudiantes. Debido al exceso de información que les dificulta el recordar, relacionar y evaluar los contenidos de una disciplina, urge diversificar estrategias pedagógicas que proporcionen aprendizajes significativos y favorezcan las potencialidades del individuo.

En los estudiantes de educación superior se ha observado poco interés en el proceso de aprendizaje, se encuentran desmotivados y pasivos; de ahí que es necesario transformar el ambiente en el aula e incluir actividades motivadoras, por ello el objetivo del presente trabajo se centra en el juego como estrategia de motivación y en consecuencia facilitar el aprendizaje significativo de los alumnos de bacteriología veterinaria y evaluar el grado de satisfacción por esta estrategia académica.

Los sistemas de educación están en una constante transformación por: los avances científicos y tecnológicos. Dichos eventos llevaron a replantear los programas educativos, con base en un modelo de aprendizaje con enfoque basado en competencias que centra el currículo en el alumno. En dicho proceso educativo, las competencias se construyen en la convergencia de los conocimientos, las habilidades y los valores (Retana, 2011). Además en este modelo se plantea el reto de lograr estimular la creatividad, la innovación y la potencialidad que tiene el ser humano.

Para el logro de competencias, el aprendizaje debe estar centrado en el estudiante, fundamentado en metodologías que promuevan autonomía e independencia; debe ser activo, vivencial y basado en problemas con el fin de obtener logros eficaces y duraderos.

Las teorías constructivistas destacan que el estudiante consigue aprendizajes significativos cuando relaciona el material a aprender con sus estructuras de conocimiento y lo transforma. De ahí que el conocimiento es un proceso activo, mediante el cual los individuos construyen explicaciones viables a sus experiencias.
Ausubel (1978) señala que el conocimiento procede de la interacción con el objeto, la relación con lo previo y la disposición del estudiante por aprender algo nuevo. Por lo que es necesario fomentar en el estudiante motivos para aprender que se relacionan con sus experiencias subjetivas, su disposición y razones para involucrarse en las actividades académicas. Es por eso que el docente debe emplear estrategias que mantengan al alumno interesado, ya que la motivación se active de manera automática (Díaz Barriga et al., 2002).

La es necesaria para garantizar el aprendizaje, si un estudiante se encuentra motivado, el beneficio de la actividad académica aumenta, lo que permite explicar la medida en que los alumnos invierten su atención y esfuerzo en determinados proyectos. Los docentes deben ocuparse de mantener activos a los estudiantes, de motivarlos y captar su interés en el área o disciplina mediante el empleo de diferentes estrategias y actividades que les permitan adquirir y fortalecer sus conocimientos, habilidades y valores.

Los seres humanos son lúdicos por naturaleza y a través del juego exploran el medio que les rodea y viven experiencias diferentes. Al jugar las personas disfrutan, se sienten libres y desarrollan habilidades. En el ámbito educativo el juego resulta valioso como elemento metodológico, constituye una forma de comunicación entre los alumnos, facilita el trabajo en equipo y es un instrumento de asimilación e integración de conocimientos.

La introducción del juego en el aula se ha utilizado como herramienta para incrementar la concentración e influir en el comportamiento del alumno favoreciendo su participación, incrementando su motivación e interés, mejora el desarrollo cognitivo, la retención y el aprendizaje social (Madani et al., 2017). Para Villalustre \& Del Moral, (2015) el juego es considerado como un potencializador de la enseñanza en el aula.

El docente debe despertar en el alumno el deseo de aprender, de investigar y de comprender. Por lo antes mencionado. Los juegos de mesa son una buena opción para favorecer el rendimiento académico, ya que pueden ser adaptados y dirigidos a los contenidos académicos, áreas disciplinares y al desarrollo de habilidades en contextos activos, atractivos e interactivos.

MORÁN-SALAS, María Cristina, MOYA-JIMÉNEZ, Carlos Roberto y LEY-FUENTES, Martha Georgina. Experiencia sobre el empleo de juegos en la educación superior. Revista de Ciencias de la Educación. 2019 
El empleo de juegos de mesa adaptados facilita la adquisición de conocimientos, la capacidad de análisis, la creatividad y la motivación en los estudiantes (Oroz et al., 2019). Igualmente, Castillo et al. (2018) en sus investigaciones mencionan que el juego educativo Armando A. Nutricio es una herramienta útil para adquirir conocimientos sobre hábitos saludables.

El aprendizaje basado en juegos consiste en el uso de estos en el aula ya sean creados específicamente o adaptando los ya existentes. Las ventajas de transformar los juegos de mesa conocidos por un lado simplifica el trabajo creativo para la consecución de objetivos de aprendizaje, en donde el juego es parte central y se acompaña de elementos de apoyo como la secuenciación, la sistematización y la evaluación de la actividad, entre otras (Tena et al., 2018).

Además, para tener éxito en los juegos de mesa adaptados, los estudiantes necesitan comprender las reglas que se utilizarán en cada partida, tener conocimiento del tema, trabajar en equipo y realizar un análisis de las tareas claves para ganar el juego (Vélez et al., 2019).

\section{Objetivo}

El objetivo de este trabajo fue facilitar el aprendizaje y motivar la participación de los estudiantes, empleando como herramienta pedagógica los juegos de mesa, adaptados por los estudiantes con temáticas de bacteriología veterinaria.

\section{Metodología desarrollada}

Esta investigación se caracteriza por el interés de aplicación de conocimientos teóricos de bacteriología y sigue un diseño descriptivo cuantitativo.

Muestra: El presente estudio parte de una estrategia pedagógica aplicada a un grupo de estudiantes de tercer semestre que cursan la asignatura de bacteriología veterinaria, adscrita a la Licenciatura de Medicina Veterinaria y Zootecnia del Centro Universitario de Ciencias Biológicas y Agropecuarias de la Universidad de Guadalajara. La implementación se llevó a cabo en el calendario escolar 2019A. Se realizó en dos etapas:
Primera etapa: El grupo de estudio estuvo conformado por 33 alumnos que trabajaron en forma individual y en equipo, investigando y analizando los juegos de mesa que les fueran conocidos y atractivos. Seleccionaron uno y lo adaptaron con contenidos temáticos de relevancia en bacteriología.

Segunda etapa: En clase se empleó un pretest de 20 preguntas para determinar el punto de partida del conocimiento de bacteriología en el alumnado, seguido de la aplicación de todos los juegos adaptados, donde los jugadores se organizaron entre ellos mismos y solo contaron con el acompañamiento y asesoría del docente en casos necesarios. Posteriormente, se utilizó un postest y se compararon los resultados obtenidos. Para el análisis estadístico se realizó mediante comparación de medias de dos muestras emparejadas y una significancia del $95 \%$.

Para evaluar las opiniones y el grado de satisfacción del material didáctico se empleó una encuesta individual, online anónima, con preguntas de opción múltiple y escala tipo Likert.

\section{Resultados}

Los juegos de mesa tradicionales seleccionados por los estudiantes para adaptarlos a las temáticas fueron: Lotería, Memorama, Turista, Jenga, Adivina ¿Quién? y Headbands. El promedio de las calificaciones obtenidas antes y después de los juegos de mesa evidencian un aumento significativo $(p<0.195$ E-08) en el puntaje del grupo (gráfico 1).

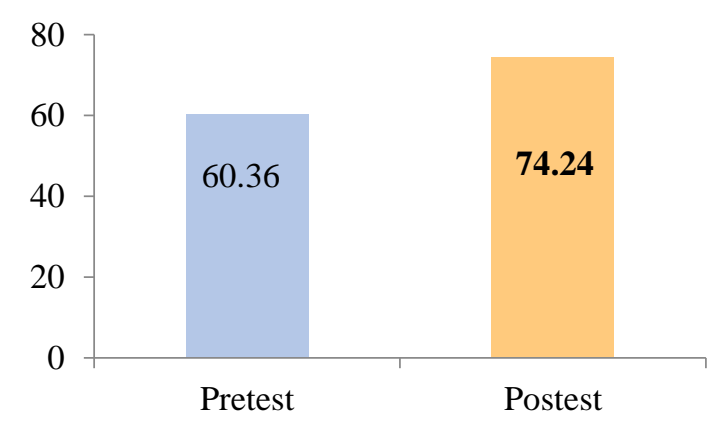

Gráfico 1 Evolución estadística de los promedios de aprobación de la asignatura de bacteriología

Con relación a los resultados de la encuesta aplicada a los estudiantes respecto a la metodología empleada en el curso, el $91 \%$ considera la estrategia útil y atractiva. 


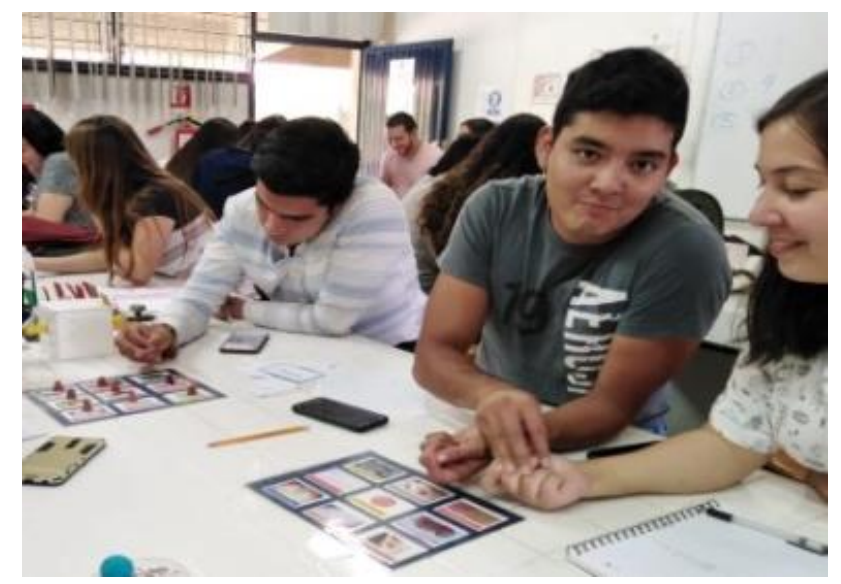

Figura 1 Sesión de juego durante el curso

Asimismo, manifestaron que los juegos adaptados en su mayoría les apoyaron a incrementar sus conocimientos (gráfico 2), en especial el Headbands (87.88\%) y Jenga (80\%).

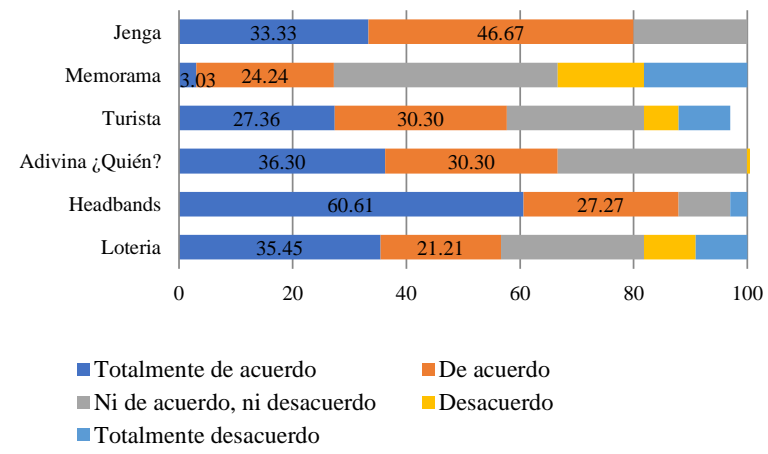

Gráfico 2 Distribución de las frecuencias sobre la valoración del incremento de conocimientos al emplear juegos de mesa

Los alumnos mencionan que con la estrategia empleada desarrollaron sus habilidades de colaboración y trabajo en equipo (gráfico 3), principalmente al jugar Headbands $(90.91 \%)$ y en menor grado con el Jenga (45.45\%).

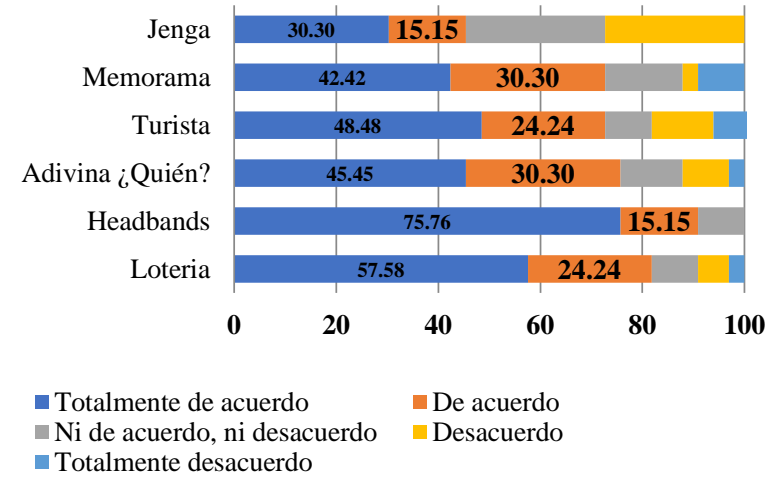

Gráfico 3 Distribución de las frecuencias sobre la valoración del desarrollo de habilidades de colaboración y trabajo en equipo al emplear juegos de mesa
Los estudiantes sintieron que desarrollaron su creatividad con el empleo de juegos de mesa (gráfico 4), especialmente con el Headbands (81.81\%), seguido del Jenga (63.63\%) y Adivina ¿Quién? (60.6\%)

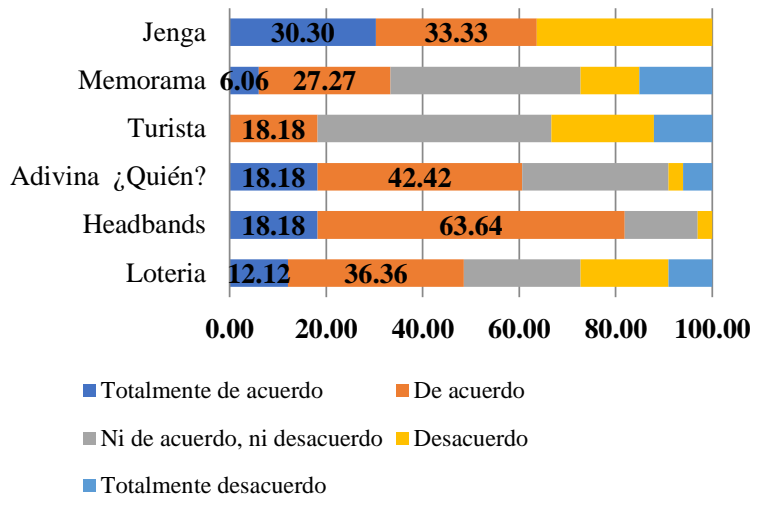

Gráfico 4 Distribución de las frecuencias sobre la valoración del desarrollo de la creatividad al emplear juegos de mesa

$\mathrm{Al}$ indagar en los alumnos la motivación generada por el uso de juegos de mesa, el $83 \%$ manifestó sentirse motivado. Esta motivación difiere de acuerdo al juego empleado. El Jenga motivo a todos los participantes, el Headbands al 93.94\%, Adivina ¿Quién? al $84.85 \%$ y en menor porcentaje $(30.3 \%)$ por el Memorama (gráfico $5)$.

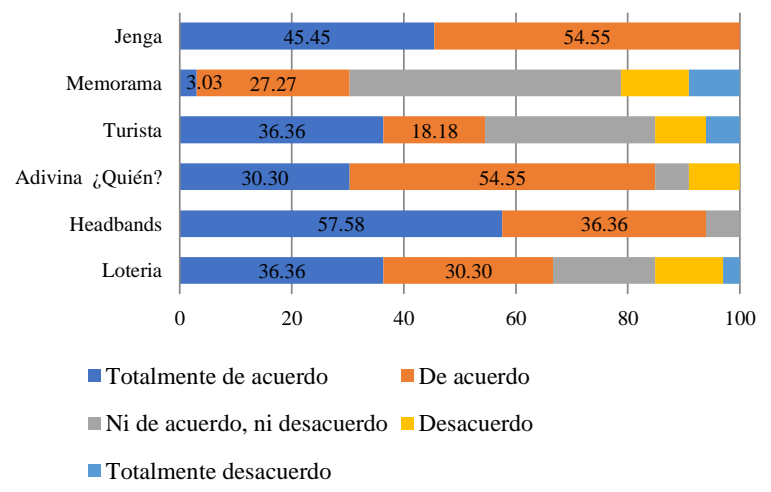

Gráfico 5 Distribución de las frecuencias sobre la valoración de la motivación presentada en los estudiantes al emplear juegos de mesa

\section{Discusión}

El empleo de los juegos de mesa adaptados a la bacteriología permitió incrementar el conocimiento de los estudiantes, situación similar a lo reportado por Duval et al. (2019) en el que mencionan que los juegos favorecen la apropiación de nuevos conocimientos conceptuales. 
De igual forma Ocampo \& Vargas (2019) en sus investigaciones evidencian que los alumnos mejoraron sus calificaciones y disminuyeron las fallas en sus pruebas escritas cuando emplearon el juego de batalla naval.

En lo referente a la aceptación del empleo de juegos en el aula, la mayoría (91\%) de los estudiantes manifestaron que estas herramientas son útiles y atractivas, dichos resultados son similares a los reportados en educación media superior por Zagarra (2017).

Al igual que lo observaron Oroz et al. (2019) a lo largo de las actividades de adaptación del juego se observó que el trabajo en equipo favoreció el ambiente de aprendizaje en el que los integrantes trabajaron en forma colaborativa analizando los diferentes conceptos de bacteriología e integrando las características de las bacterias con las especies animales afectadas y la patología que pueden producir en el individuo. Asimismo, se fortalecieron los valores como el respeto, confianza y compromiso al igual que en las investigaciones realizadas por Miranda et al. (2018) en las cuales se indican que a través de los juegos se pueden desarrollar valores.

Los juegos de mesa motivaron a los estudiantes y desencadenaron emociones que produjeron cambios que modificaron positivamente su actitud, lo cual les permitió aprender mejor.

\section{Agradecimiento}

Este trabajo ha sido posible gracias al apoyo del Departamento de Medicina Veterinaria, adscrito al Centro Universitario de Ciencias Biológicas y Agropecuaria y al Sistema de Universidad Virtual de la Universidad de Guadalajara.

\section{Conclusiones}

La adecuación de los juegos de mesa conocidos por los estudiantes y su aplicación en el aula resultó ser una herramienta de apoyo a la enseñanza que mejora el aprendizaje significativamente $(p<0.195 \mathrm{E}-08)$.
Los juegos de mesa empleados como herramienta pedagógica contribuyeron a crear un entorno agradable e incrementar la motivación y la participación de los estudiantes, y se desarrollaron habilidades sociales, aumentando el grado de integración de los miembros del grupo y mejorando el clima de convivencia en el aula.

\section{Referencias}

Ausbel, D. (1978). Psicología Educativa: Una visión cognitiva, Ed. Trillas, México.

Castillo, S. E. A., Castillo-Ruiz, O., de León, J. A. R., Marín, R. M. U., \& de la Cruz, G. V. (2018). Aplicación de un juego de mesa para enseñar conceptos de nutrición y actividad física a niños de escuela primaria y secundaria. CIENCIA ergo-sum, Revista Científica Multidisciplinaria de Prospectiva, 25(2).

Díaz-Barriga Arceo, F., \& Hernández Rojas, G. (2002). Estrategias docentes para un aprendizaje significativo. Una interpretación constructivista. $2^{\mathrm{a}}$. Ed. McGraw Hill, México.

Duval, V. S., Alcaráz, G. V. Y., Casado, A., \& de la Puente, F. J. B. (2019). El Juego de la Carta Topográfica: un recurso didáctico para la enseñanza de la cartografía desde la Geografía. Geográfica digital, 16(31), 46-54.

Madani, K., Pierce, T. W. \& Mirchi, A. (2017). Serious games on environmental management. Sustainable Cities and Society, 29, 1-11.

Ocampo, Y. M. O., \& Vargas, C. A. Á. (2019). Aprendizaje de coordenadas absolutas y relativas empleando el juego de estrategia Batalla Naval. Revista Educación en Ingeniería, 14(28), 72-77.

Oroz, D. R., Espina, R. G., Pérez, M. J. B., \& Truyol, M. E. (2019). Aprendizaje basado en un proyecto de gamificación: vinculando la educación universitaria con la divulgación de la geomorfología de Chile. Revista Eureka sobre Enseñanza y Divulgación de las Ciencias, 16(2), 220201-220213.

Retana, J. Á. G. (2011). Modelo educativo basado en competencias: importancia y necesidad/Educational model based in competency: importance and necessity. Actualidades investigativas en educación, 11(3). 
Tena, J. P. (2018). Evaluando el uso de juegos de mesa no educativos en las aulas: Una propuesta de modelo. Communication Papers, 7(14), 37.

Vélez, O. A., López, S. M. P., Fernández, Y. L. H., Rendón, P. A. O., \& Martínez, L. F. G. (2019). Aprendizaje basado en juegos formativos: caso Universidad en Colombia. REDIE: Revista Electrónica de Investigación Educativa, (21), 11.

Villalustre, L. \& Del Moral, M. (2015). Gamificación: Estrategia para optimizar el proceso de aprendizaje y la adquisición de competencias en contextos universitarios. Digital Education Review, 0(27), 13-31

Zagarra, G. J. N., Carrillo, A. R., López, L. M. F., Ontiveros, A. G., \& Tinajero, G. C. (2017). El aprendizaje lúdico en el nivel medio superior. Jóvenes en la Ciencia, 2(1), 861-873. 